\title{
Bucky ferrocene. Hybrid of ferrocene and fullerene
}

\author{
Eiichi Nakamura \\ Department of Chemistry, The University of Tokyo, Tokyo 113-0033, Japan
}

\begin{abstract}
The idea of "bucky ferrocene" intrigues chemists owing to its aesthetic beauty and to its polarized, extended conjugated system, but the idea has remained hypothetical. The synthesis of close analogs of $\mathrm{Fe}\left(\mathrm{C}_{60} \mathrm{Me}_{5}\right) \mathrm{Cp}$ and $\mathrm{Fe}\left(\mathrm{C}_{70} \mathrm{Me}_{3}\right) \mathrm{Cp}$ was achieved in two steps from [60] and [70]fullerenes, relying on an oxidative $\mathrm{C}-\mathrm{H}$ bond activation starting with an iron(I) complex and the corresponding cyclopentadienyl precursors, respectively. The molecules can be regarded as members of a new organometallic conjugated system connected to a graphitic system. Numerous synthetic transformations and self-organization procedures that are known for the parent ferrocenes and fullerenes are expected to be employable toward productive use of the ferrocene/fullerene hybrid molecules in chemistry and materials sciences.
\end{abstract}

\section{INTRODUCTION}

Ferrocene [1, $\mathrm{Fe}\left(\mathrm{C}_{5} \mathrm{H}_{5}\right)_{2}$, Fig. 1] was first reported 50 years ago [1]. It is composed of a pair of $6 \pi$-electron aromatic pentagonal carbon arrays (cyclopentadienide $=\mathrm{Cp}$ ) and a 6d-electron $\mathrm{Fe}(\mathrm{II})$ atom. The discovery of 1 opened a new era of chemistry and established the concept of $\mathrm{p} \pi / \mathrm{d} \pi$ complexes. $\mathrm{C}_{60}$ Fullerene (2, Fig. 1) is another class of $\pi$-conjugated system that was discovered in 1985 [2], and has a total of $60 \pi$-electrons and 12 pentagonal $\mathrm{sp}^{2}$ carbon arrays. The notion of a ferrocene/fullerene hybrid through face-to-face fusion of the two molecules to make "bucky ferrocene" $\mathbf{3}$ is intriguing (Fig. 1), since such a molecule would enjoy the rich scientific heritage of both ferrocene and fullerene. This molecule 3 is expected to be very unstable owing to the curved surface of the fullerene [3]. We report here that ferrocene/fullerene hybrid molecules can be synthesized as stable molecules by the use of fullerene derivatives possessing a suitable number of electrons so that they can act as a $6 \pi$-electron donor ligand to the 6d-electron Fe(II) atom. Organic modification of the fullerene core toward the desired Cp embedded in the fullerene core, their intriguing properties, and organometallic synthetic studies toward the goal of "bucky ferrocene" are described in this review [4].

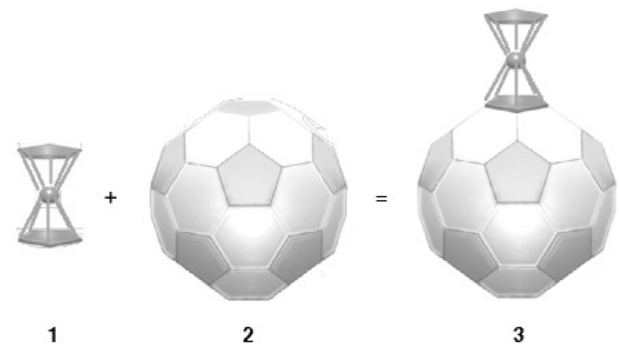

Fig. 1 An equation leading to the formation of "bucky ferrocene".

\footnotetext{
*Plenary lecture presented at the $\mathrm{XX}^{\text {th }}$ International Conference on Organometallic Chemistry (ICOMC), Corfu, Greece, 7-12 July 2002. Other presentations are published in this issue, pp. 421-494.
} 


\section{TRI- AND PENTA-ADDITION OF ORGANOCOPPER REAGENT}

In spite of intense activity in covalent functionalization of carbon clusters [5], the major problem still is the yield of the synthetic transformations, which is generally far from the ideal. In order for the carbon cluster science to become truly useful core technology in the $21^{\text {st }}$ century, the synthetic transformations must be quantitative based on the starting carbon cluster and must be achieved in a simple and efficient procedure without production of noxious waste. With virtually no exceptions, the reported synthetic transformations of carbon clusters produce the desired product together with over-reacted products, recovered starting material, and regio- and stereoisomers.

We previously reported that [60]fullerene reacts with a phenyl Grignard reagent in the presence of a $\mathrm{Cu}(\mathrm{I})$ salt to form a penta-addition product $\mathrm{C}_{60} \mathrm{Ph}_{5} \mathrm{H}$ in $98 \%$ isolated yield based on analytically pure product [6]. The reaction can be easily performed on a 10-g scale in a usual chemical laboratory. This transformation represented, to our knowledge, the only chemical transformation at that time that enables covalent functionalization of carbon clusters in quantitative yield. The reaction was proven to be applicable to the synthesis of a variety of a $\mathrm{C}_{60} \mathrm{R}_{5} \mathrm{H}$ compounds $(\mathbf{4}$, denoted as $\mathrm{RFCpH}, \mathrm{R}=$ aryl, methyl and 1-alkenyl) often in a quantitative yield [6b,7].

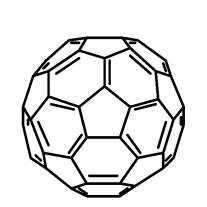

2

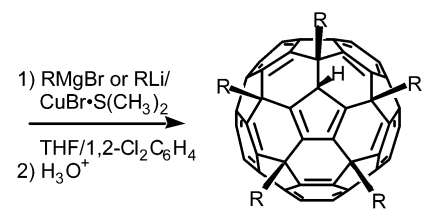

$4 \mathrm{C}_{60} \mathrm{R}_{5} \mathrm{H}(\mathrm{RFCpH})$

$\mathrm{a}: \mathrm{R}=\mathrm{Ar}, \mathrm{b}: \mathrm{R}=\mathrm{Me}, \mathrm{c}: \mathrm{R}=1$-alkenyl

Continuing the studies, we then discovered another transformation wherein [70]fullerene (5) reacts with a Grignard reagent in the presence of a $\mathrm{Cu}(\mathrm{I})$ salt [8]. The product was, however, not the expected penta-adduct but a tri-adduct $\mathrm{C}_{70} \mathrm{R}_{3} \mathrm{H}(\mathbf{6})$. Thus, the addition reaction took place $100 \%$ selectively on the side of the football-shaped fullerene rather than at the pointed end of the molecule, and stopped precisely after tri-addition. The tri-addition was made to proceed in $90-99 \%$ isolated yield for methyl and aryl Grignard reagents. The reaction provided the second example of quantitative covalent functionalization of carbon clusters, which was followed later by the third example, quantitative tetraamination reaction of $\mathrm{C}_{60}$ fullerene [9]. Tri-addition product was also obtained from [60]fullerene through a little elaborate synthetic sequence [7b].

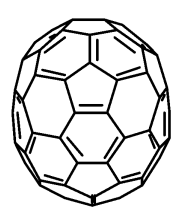

5

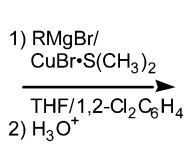

2) $\mathrm{H}_{3} \mathrm{O}^{+}$

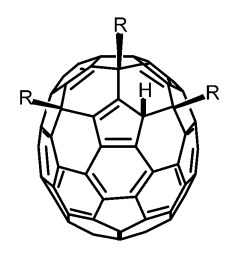

$6 \mathrm{C}_{70} \mathrm{R}_{3} \mathrm{H}$

$\mathrm{a}: \mathrm{R}=\mathrm{Ar} \mathrm{b}: \mathrm{R}=\mathrm{Me}$

\section{UNUSUAL STABILITY OF CYCLOPENTADIENIDE IN WATER: FULLERENE VESICLES}

The penta-adduct, which serves as a precursor to the pentahaptofullerene metal complexes $\mathrm{M}\left(\eta^{5}-\mathrm{C}_{60} \mathrm{R}_{5}\right)$, are useful for nanostructures in water [10] and on the surface [11]. The pentaaryl- and pentamethyl fullerene anions $\mathrm{K}^{+} \mathrm{RFCp}^{-}(\mathbf{7}, \mathbf{a}: \mathrm{R}=\mathrm{Ar}, \mathbf{b}: \mathrm{R}=\mathrm{Me})$ show remarkable stability and solubility in water. The stability of the anions is due to the intrinsically high stability of the Cp anion through delocalization of the negative charge toward the $50 \pi$-electron system at the bottom of the $\mathrm{C}_{60}$ cage through "endohedral homoconjugation" [12]. Being composed solely of carbon atoms and hydro- 
gen atoms, these compounds represent a rare example of hydrocarbon anions with well-defined water solubility.

This unique type of water-soluble fullerenes is not only expected to exhibit diverse biological activities [13], but also able to form ordered aggregate structure that can be utilized in materials science. The atomic microscopic image of the solution on mica surface (Fig. 2) shows half-spherical objects corresponding to the aggregates of the Cp. A typical object measures $70 \mathrm{~nm}$ in diameter and $10 \mathrm{~nm}$ in height (roughly corresponding to a radius of $17 \mathrm{~nm}$ for a spherical object).

A laser light-scattering study revealed a unique association behavior of the potassium salt of pentaphenylfullerene anions $\mathrm{K}^{+} \mathrm{PhFCp}^{-}$in water. By using a combination of both static and dynamic lightscattering measurements, we have determined the size, size distribution, and shape of the associated particles. The critical aggregation concentration and the average aggregation number of the aggregated particles were also estimated.

Two species could be determined in the aqueous solutions of hydrocarbon anions of $\mathrm{Ph}_{5} \mathrm{C}_{60}{ }^{-}$, respectively, unimers with $\langle\mathrm{Rh}>\sim 1 \mathrm{~nm}$ and spherical aggregate particles with $<\mathrm{Rh}>\sim 17 \mathrm{~nm}$ and polydispersity $\mu_{2} /\langle\Gamma\rangle^{2} \sim 0.12 \pm 0.3$. The association of the $\mathrm{K}^{+} \mathrm{PhFCp}^{-}$in water could occur at very low concentration, e.g., less than $1 \times 10^{-7} \mathrm{~mol} / \mathrm{L}$. The average aggregation number of the associated particles was estimated to be about $1.2 \times 10^{4}$. The associated particles suspended in water are very stable, for example, the size and size distribution remained the same after settling at room temperature for one month.

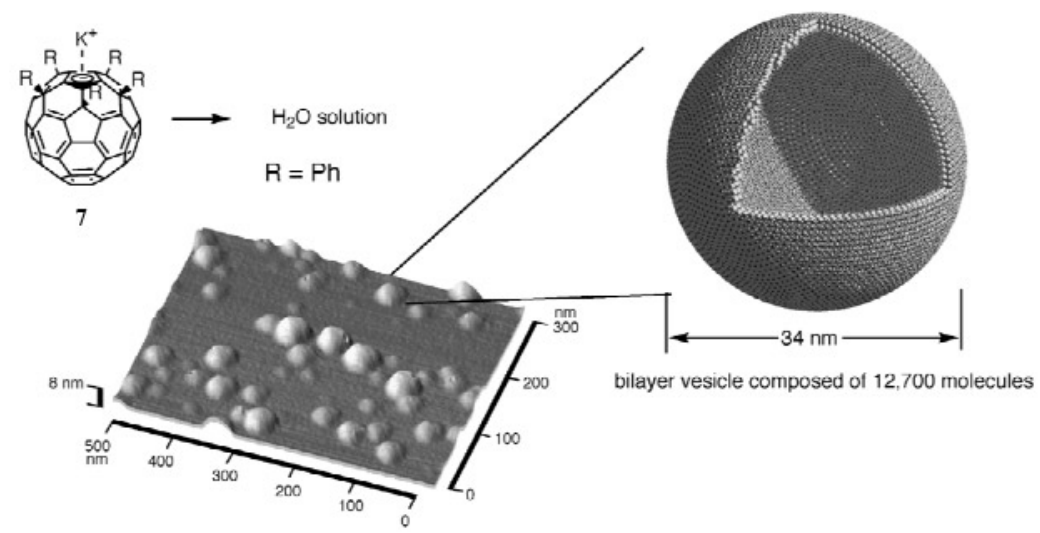

Fig. 2 Vesicles of $\mathrm{K}^{+} \mathrm{PhFCp}^{-}$in water. AFM image on mica and the size determined by LLS.

\section{RHODIUM COMPLEX: A STEP TOWARD BUCKY FERROCENE}

While the synthesis of various main group metal FCp complexes was rather easy, the synthesis of transition-metal complexes turned out to be quite difficult. Several earlier attempts to synthesize the desired bucky ferrocene failed completely. Assuming that this failure is due to a steric problem which later turned out to not be the real issue, we started to work on less sterically hindered metal complexes. One successful example is the synthesis of the first transition-metal FCp complex $\mathrm{Rh}\left(\eta^{5}-\mathrm{MeFCp}\right)(\mathrm{CO})_{2}(\mathbf{8})$ [14]. $\mathrm{Rh}\left(\eta^{5}-\mathrm{MeFCp}\right)(\mathrm{CO})_{2}$ (8) was prepared through the transmetalation of KMeFCp with $\mathrm{Rh}_{2} \mathrm{Cl}_{2}(\mathrm{CO})_{4}$ in hexamethylphosphoramide at $55^{\circ} \mathrm{C}$ for $19 \mathrm{~h}$. The complex was isolated in $51 \%$ yield (based on $\mathrm{MeFCpH}$ ) after aqueous work-up followed by preparative HPLC separation. Further purification by recrystallization from $\mathrm{CS}_{2} / \mathrm{Et}_{2} \mathrm{O}$ gave wine-red crystals of $\mathbf{8}$. This transition-metal complex $\mathbf{8}$ is stable against both air and mildly acidic and basic aqueous medium. The complex $\mathbf{8}$ possesses an extended electronic array including the bottom $\mathrm{C}_{50}$ core, the $\mathrm{Cp}$, the rhodium metal, and the two $\mathrm{CO}$ ligands. The system is robust under the conditions of two-electron oxidation/reduction, allowing the 
MeFCp complex to be oxidized and reduced without loss of the transition-metal atom. Such stability against redox conditions is prerequisite for the use of a FCp transition-metal complex for catalysis.

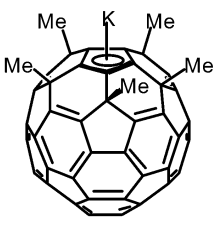

$7 \mathrm{~b}$

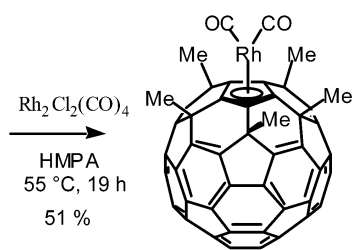

8

Molecular structure of $\mathrm{Rh}\left(\eta^{5}-\mathrm{MeFCp}\right)(\mathrm{CO})_{2}(\mathbf{8})$ was determined by X-ray diffraction (Fig. 3). The rhodium atom is bonded to the $\mathrm{Cp}$ carbon atoms $[\mathrm{C}(\mathrm{Cp})]$ in an $\eta^{5}$-fashion with an averaged interatomic distance of $2.19 \AA$. One of the five $\mathrm{C}(\mathrm{Cp})$ atoms is slightly above the $\mathrm{Cp}$ plain, is bent toward the rhodium atom, and is bonded to the rhodium atom with the Rh-C distance of $2.12 \AA$. The averaged value of $\mathrm{Rh}-\mathrm{C}(\mathrm{Cp})$ distances is $3 \%$ and $5 \%$ shorter than the corresponding values of $\mathrm{Rh}\left(\eta^{5}-\mathrm{C}_{5} \mathrm{Me}_{5}\right)(\mathrm{CO})_{2}(2.26 \AA)$ and $\mathrm{Rh}\left(\eta^{5}-\mathrm{C}_{5} \mathrm{Ph}_{5}\right)(\mathrm{CO})_{2}(2.29 \AA)$, respectively. Another striking feature is the high degree of pyramidalization of the $\mathrm{Cp}$ carbons toward the Rh metal [the $\mathrm{C}(\mathrm{Cp})-\mathrm{C}(\alpha)$ bonds are pushed by average $22.6^{\circ}$ down from the $\mathrm{Cp}$ plane]. This bending, in turn, pushes the five methyl groups far from each other, keeping a wide space for the metal and the ligands. This space looks wide enough to allow the metal to undergo ligand exchange and chemical reactions. With the short Rh-C(Cp) distance as well as the ${ }^{13} \mathrm{C}$ NMR data, we conclude that the rhodium atom is covalently bonded to the MeFCp ligand.

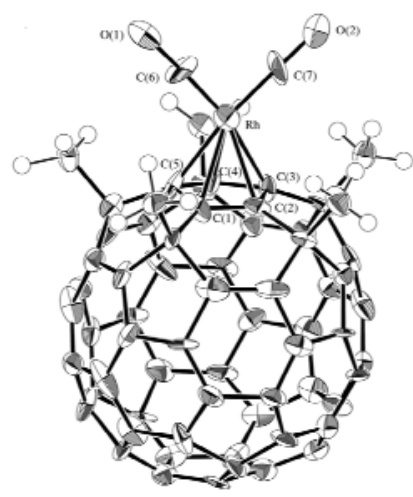

Fig. 3 Crystal structure of $\mathrm{Rh}\left(\mathrm{Me}_{5} \mathrm{C}_{60}\right)(\mathrm{CO})_{2}$.

\section{SYNTHESIS AND PROPERTIES OF BUCKY FERROCENE}

The thallium complex of pentamethylated [60]fullerene $\mathrm{Tl}(\mathrm{MeFCp})(9)$ is quantitatively available in two steps from [60]fullerene. When 9 and $\mathrm{FeBrCp}(\mathrm{CO})_{2}$ were heated in 1,2-dichlorobenzene at $120^{\circ} \mathrm{C}$ for $24 \mathrm{~h}, \mathrm{Fe}(\mathrm{MeFCp}) \mathrm{Cp}(\mathbf{1 0})$ was obtained in $10 \%$ yield as an orange solid [15]. Whereas recent theo-

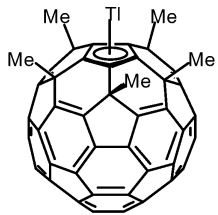

9

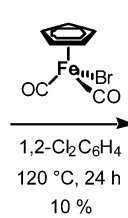

$10 \%$

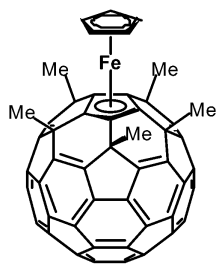

10

(C) 2003 IUPAC, Pure and Applied Chemistry 75, 427-434 
retical studies have suggested that bucky ferrocene would be thermodynamically rather unstable [3], 10 was in fact extremely stable: No decomposition took place after standing for many months in air, after heating at $200{ }^{\circ} \mathrm{C}$ for $1 \mathrm{~h}$ in vacuo, or after irradiation in benzene with a high-pressure mercury lamp under nitrogen for $15 \mathrm{~h}$.

Having failed to further optimize the metathesis route, we discovered an oxidative $\mathrm{C}-\mathrm{H}$ bond activation route starting with $\mathrm{C}_{60} \mathrm{Me}_{5} \mathrm{H}(\mathbf{4 b})$ and of $\left[\mathrm{FeCp}(\mathrm{CO})_{2}\right]_{2}$, replacing the cyclopentadienyl hydrogen atom with the $\mathrm{FeCp}$ fragment of the $\mathrm{Fe}(\mathrm{I})$ complex. The conversion of $\mathbf{4 b}$ to $\mathbf{1 0}$ was achieved as a g-scale reaction in benzonitrile at $180{ }^{\circ} \mathrm{C}$ for $8 \mathrm{~h}$ to obtain $\mathbf{1 0}$ in $52 \%$ isolated yield. Thus, $\mathbf{1 0}$ was obtained in two steps from $\mathrm{C}_{60}$ fullerene in $45 \%$ overall yield.

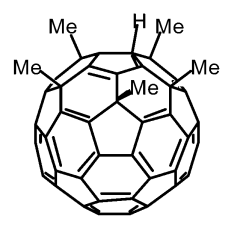

4b

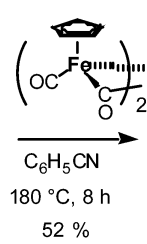

$52 \%$

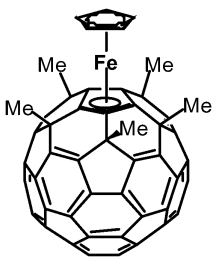

10

Recrystallization of $\mathbf{1 0}$ from $\mathrm{CS}_{2}$ /ethanol afforded single dark-red crystals composed of a 1:1 mixture of $\mathbf{1 0}$ and $\mathrm{CS}_{2}$. The X-ray crystal structure of $\mathbf{1 0}$ is shown in Fig. 4. The five methyl groups attached to five $\mathrm{sp}^{3}$ carbon atoms protrude outward at an angle of $42{ }^{\circ} \mathrm{C}$ relative to the symmetry axis of the molecule, and the methyl and $\mathrm{Cp}$ hydrogen atoms are in van der Waals contact with each other. The $\mathrm{Cp}$ group and $\mathrm{Cp}$ in $\mathrm{FCp}$ are arranged in a staggered manner. The distances between the pentagon carbon atoms and the iron $(2.033 \AA$ for $\mathrm{Cp}-\mathrm{Fe}$, and $2.089 \AA$ for $\mathrm{FCp}-\mathrm{Fe})$ are comparable to those in known ferrocene derivatives. One reason for the longer FCp-Fe bond may be the nonplanarity of the bottom $\mathrm{Cp}$ in $\mathrm{FCp}$, which forces the $2 \mathrm{p}$ carbon orbitals away from the iron atom.

The ${ }^{1} \mathrm{H}$ and ${ }^{13} \mathrm{C}$ NMR spectra at -50 and $30{ }^{\circ} \mathrm{C}$ indicated that 10 has $C_{5 \mathrm{v}}$ symmetry (only $\mathbf{1 0}$ ${ }^{13} \mathrm{C}$ NMR signals), and that the methyl groups rotate freely (a single signal at $\delta 2.51 \mathrm{ppm}$ ). The Cp protons resonate at $\delta 4.86 \mathrm{ppm}$, which clearly demonstrates the aromaticity of the $6 \delta$-Cp group. In addition, the signal is notably shifted downfield compared with normal ferrocene $1(\delta 4.16 \mathrm{ppm})$. The ${ }^{13} \mathrm{C}$ NMR signal of the $\mathrm{C}(\mathrm{Cp})$ atoms $(\delta 77.54 \mathrm{ppm})$ is also at a lower field than in ferrocene $\mathbf{1}(\delta 67.91 \mathrm{ppm})$, and the $\mathrm{C}(\mathrm{Cp})$ in $\mathrm{FCp}$ resonate even more downfield $(\delta 91.86 \mathrm{ppm})$. These findings suggest that the fullerene core withdraws an electron from the ferrocene moiety.

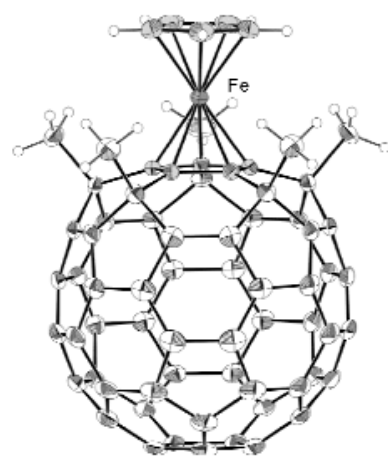

Fig. 4 Crystal structure of Fe(MeFCp)Cp.

In order to synthesize a closer analog of the parent "bucky ferrocene" 3 where the one Cp moiety of ferrocene is directly conjugated with fullerene, we focused our attention on the trimethylated 
$\mathrm{C}_{70}$ fullerene $\mathrm{C}_{70} \mathrm{Me}_{3} \mathrm{H}(\mathbf{6 b})$. The metathesis approach failed entirely for the synthesis of 11. Instead, we treated $\mathrm{C}_{70} \mathrm{Me}_{3} \mathrm{H}(\mathbf{6 b})$ with $\left[\mathrm{FeCp}(\mathrm{CO})_{2}\right]_{2}$ in benzonitrile at $160{ }^{\circ} \mathrm{C}$ for $21 \mathrm{~h}$ to obtain 11 in $31 \%$ isolated yield as a dark brown solid (Fig. 1). An overall yield of the two-step synthesis from $\mathrm{C}_{70}$ fullerene was $27 \%$. ${ }^{1} \mathrm{H}$ and ${ }^{13} \mathrm{C}$ NMR spectra at $25{ }^{\circ} \mathrm{C}$ indicated that $\mathbf{1 1}$ is $C_{\mathrm{s}}$ symmetric, and that the methyl groups rotate freely.

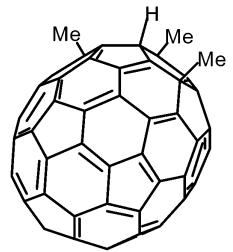

6b

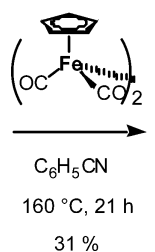

$31 \%$

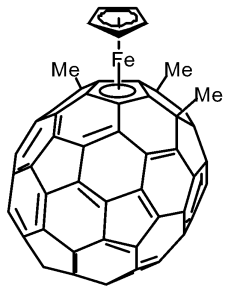

11

Recrystallization of $\mathbf{1 1}$ from $\mathrm{CS}_{2}$ /pentane afforded single dark-red crystals composed of a 1:1 mixture of $\mathbf{1 1}$ and $\mathrm{CS}_{2}$. The X-ray crystal structure of $\mathbf{1 1}$ is shown in Fig. 5. The structural features of the ferrocene moiety in $\mathbf{1 1}$ are similar to those of $\mathrm{Fe}\left(\eta^{5} \text {-indenyl }\right)_{2}(\mathbf{1 2})$. The distances between the pentagon carbon atoms and the iron (average $2.054 \AA$ for $\mathrm{Cp}-\mathrm{Fe}$, and $2.083 \AA$ for fullerene $\mathrm{Cp}$ - $\mathrm{Fe}$ ) as well as the $\mathrm{C}-\mathrm{C}$ bond lengths in the $\mathrm{Cp}$ ligand, $1.41-1.43 \AA$, are comparable to those of ferrocene and $\mathbf{1 2}$. A small but significant difference between $\mathbf{1 2}$ and $\mathbf{1 1}$ is that the $\mathrm{Cp} \mathrm{C}-\mathrm{C}$ bond (1.458 $\AA$, Fig. 6A) connected to a hexagon in the "belt region" of $\mathrm{C}_{70}$ fullerene core is slightly longer than the remaining four $\mathrm{C}-\mathrm{C}$ bonds in the pentagon, a feature known for indenyl iron complexes (Fig. 6B) [16]. Bond alternation found in the six-membered ring next to the $\mathrm{Cp}$ moiety is another characteristic of an indenyl complex. Thus, $\mathbf{1 1}$ can be regarded as a "super-indenyl" Fe(II) complexes or alternatively as a member of new organometallic conjugated systems incorporated into graphitic structure.

Fig. 5 Crystal structure of $\mathrm{Fe}\left(\mathrm{C}_{70} \mathrm{Me}_{3}\right) \mathrm{Cp}$.

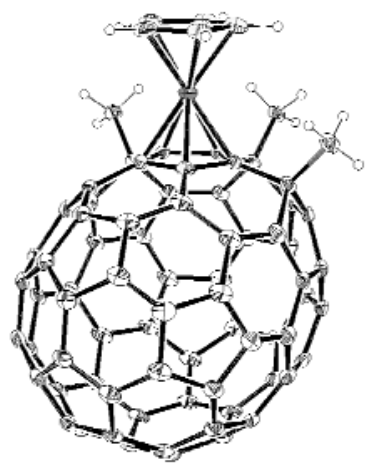

A

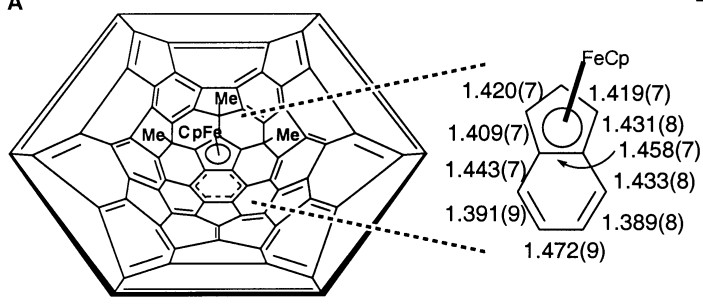

B Fe $\left(\eta^{5} \text {-indenyl }\right)_{2}$

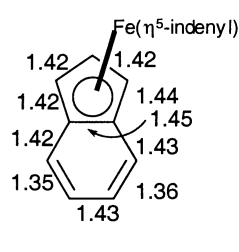

Fig. 6 Partial structure of $\mathrm{Fe}\left(\mathrm{C}_{70} \mathrm{Me}_{3}\right) \mathrm{Cp}$. 


\section{CONCLUSION}

We have synthesized a class of new organometallic $\mathrm{d} \pi / \mathrm{p} \pi$-systems that are incorporated in graphitic structures through face-to-face fusion of ferrocene and fullerene. Given the versatility of ferrocene and fullerenes, we anticipate that these hybrid molecules will serve as key compounds for catalysis and materials science. The synthetic methodologies proven for $\mathrm{C}_{60}$ and $\mathrm{C}_{70}$ fullerene derivatives would be applicable to the construction of ferrocene structures on higher fullerenes and on the end cap region of carbon nanotubes and nanohorns.

\section{ACKNOWLEDGMENTS}

We thank our able collaborators, whose names are listed in the references, for their devotion to the science described above, Monbusho (Grant-in-Aid for Special Scientific Research) for financial support, the Institute for Molecular Science, and the Intelligent Modeling Laboratories of the University of Tokyo for generous allotment of computer time.

\section{REFERENCES}

1. (a) H. Iikura, S. Mori, M. Sawamura, E. Nakamura. J. Org. Chem. 62, 7912 (1997); (b) T. J. Kealy, P. L. Pauson. Nature 168, 1039 (1951); (c) S. A. Miller, J. A. Tebboth, J. F. Tremaine. J. Chem. Soc. 632 (1952); (d) G. Wilkinson, M. Rosenblum, M. C. Whiting, R. B. Woodward. J. Am. Chem. Soc. 74, 2125 (1952); (e) E. O. Fischer and W. Z. Pfab. Z. Naturforsch. 7B, 377 (1952).

2. H. W. Kroto, J. R. Heath, S. C. O’Brien, R. F. Curl, R. E. Smalley. Nature 318, 162 (1985).

3. E. D. Jemmis, K. Manoharan, P. K. Sharma. Organometallics 19, 1879 (2000).

4. (a) E. Nakamura and M. Sawamura. Pure Appl. Chem. 73, 355 (2001); (b) A. L. Balch and M. M. Olmstead. Chem. Rev. 98, 2123 (1998).

5. W. Andreoni. The Physics of Fullerene-Based and Fullerene-Related Materials, Kluwer Netherlands (2000).

6. (a) M. Sawamura, H. Iikura, E. Nakamura. J. Am. Chem. Soc. 118, 12850 (1996); (b) M. Sawamura, H. Iikura, T. Ohama, U. E. Hackler, E. Nakamura. J. Organomet. Chem. 59, 32 (2000).

7. (a) M. Sawamura, M. Toganoh, Y. Kuninobu, S. Kato, E. Nakamura. Chem. Lett. 270 (2000); (b) M. Sawamura, M. Toganoh, K. Suzuki, A. Hirai, H. Iikura, E. Nakamura. Org. Lett. 2, 1919 (2000); (c) M. Sawamura, N. Nagahama, M. Toganoh, E. Nakamura. J. Organomet. Chem. 652, 31 (2002).

8. (a) M. Sawamura, H. Iikura, A. Hirai, E. Nakamura. J. Am. Chem. Soc. 120, 8285 (1998); (b) M. Sawamura, M. Toganoh, H. Iikura, Y. Matsuo, A. Hirai, E. Nakamura. J. Mater. Chem. 12, 2109 (2002).

9. H. Isobe, N. Tomita, E. Nakamura. Org. Lett. 2, 3663 (2000); cf. H. Isobe, A. Ohbayashi, M. Sawamura, E. Nakamura. J. Am. Chem. Soc. 122, 2669 (2000).

10. (a) M. Sawamura, N. Nagahama, M. Toganoh, U. E. Hackler, H. Isobe, E. Nakamura, S. Zhou, B. Chu. Chem. Lett. 2, 1098 (2000); (b) S. Zhou, C. Burger, B. Chu, M. Sawamura, N. Nagahama, M. Toganoh, U. E. Hackler, H. Isobe, E. Nakamura. Science 291, 1944 (2001).

11. (a) T. Shimada, H. Nakatani, K. Ueno, A. Koma, Y. Kuninobu, M. Sawamura, E. Nakamura. J. Appl. Phys. 90, 209 (2001); (b) A. Fujii, T. Umeda, H. Isobe, E. Nakamura, K. Yoshino. Jpn. J. Appl. Phys. 40, L1390 (2001); (c) M. Sawamura, K. Kawai, Y. Matsuo, K. Kanie, T. Kato, E. Nakamura. Nature 419, 702-705 (2002).

12. H. Iikura, S. Mori, M. Sawamura, E. Nakamura. J. Org. Chem. 62, 7912 (1997). 
13. cf. (a) M. Matsumoto, H. Tachibana, R. Azumi, M. Tanaka, T. Nakamura, G. Yunome, M. Abe, S. Yamago, E. Nakamura. Langmuir 11, 660 (1995); (b) E. Nakamura, H. Isobe, N. Tomita, M. Sawamura, S. Jinno, H. Okayama. Angew. Chem., Int. Ed. 39, 4254 (2000); (c) H. Isobe, S. Sugiyama, K. Fukui, K. Y. Iwasawa, E. Nakamura. Angew. Chem., Int. Ed. 40, 3364 (2001); (d) H. Isobe, N. Tomita, S. Jinno, H. Okayama, E. Nakamura. Chem. Lett. 1214 (2001).

14. M. Sawamura, Y. Kuninobu, E. Nakamura. J. Am. Chem. Soc. 122, 12407 (2000).

15. M. Sawamura, Y. Kuninobu, M. Toganoh, Y. Matsuo, M. Yamanaka, E. Nakamura. J. Am. Chem. Soc. 124, 9354 (2002).

16. S. A. Westcott, A. K. Kakkar, G. Stringer, N. J. Taylor, T. B. Marde. J. Organomet. Chem. 394, 777 (1990). 